\title{
First isolation of Legionella pneumophila in Sri Lanka
}

\author{
W M P B Wahala', and R S B Wickramasinghe'
}

(Index words: Cooling towers, past infection among staff, culture, fatty acid profile of isolates).

\begin{abstract}
Objectives To determine the presence of legionellae and species composition of the genus Legionella in Sri Lankan hotel cooling towers, and to determine the previous exposure of hotel workers to Legionella pneumophila.
\end{abstract}

Design Collection of water samples from 16 cooling towers of air conditioning plants from 7 representative hotels, and blood samples from hotel workers.

Setting Department of Bacteriology, Medical Research Institute, Colombo 8.

Results Water samples from 4 (57.4\%) hotels selected were positive for legionellae. Five $(38.4 \%)$ selected cooling towers yielded legionellae with viable counts ranging from 1 to 5 colony forming units (CFU)/ml. $93.7 \%$ of the isolates were Legionella pneumophila. Only one hotel worker had significant antibody levels denoting past infection to Legionella pneumophila.

Conclusion Legionella does occur in the Sri Lankan hotel environment and Legionella pneumophila appears to be the most common species.

\section{Introduction}

Legionella pneumophila which is an important respiratory pathogen world-wide, was first identified in 1976 in the USA as a result of an outbreak of acute pneumonia (1). To date a total of 42 Legionella species have been identified and 21 of these are pathogenic in humans, producing legionellosis in either the form of Legionnaire's disease or as Pontiac fever (2). At present $L$ pneumophila' contains 15 serogroups of which serogroup (sg) 1 is the most common clinical and environment isolate world-wide, followed by sg 6 (2).

Legionellae are ubiquitous in an aquatic environment including both natural habitats such as rivers, lakes and ponds, wet soils, and man-made environments such as cooling tower systems, hot-water tanks, evaporative condensers, shower heads, humidifiers etc (3). Legionellae live in close association with free living amoebae (eg Acanthamoeba), other protozoa and cyanobacteria, and survive in them as intracellular parasites. Viable counts of legionellae have been reported more in cooling towers than in natural habitats (4). Usually Legionella infection occurs through inhalation of aerosolised bacteria by susceptible persons. Man to man spread has not been reported (5) Cooling tower systems give a better chance for the organism to grow and multiply and disseminate the bacteria by formation of aerosols, thus producing epidemics. There are, however, many instances of legionellae isolated from the cooling towers without any resulting epidemics (6).
Cooling tower and air-conditioning circuits are two separate entities. Usually cooling towers are located outside the building, and are used in a large air-conditioning system to cool the condenser of the air-conditioning circuit. When the tower is operational aerosols are generated and disseminated into the surrounding environment. If the water is contaminated with Legionella these aerosols can cause the disease.

The first serologically confirmed case of legionellosis in the country was reported in 1993 (7). Since then there have only been 4 cases (Unpublished data). Altempts at culture have not been successful. No epidemics have been reported to date. Numerous epidemiologic investigations done world-wide have convincingly shown that cooling towers can serve as a source of infection. In Sri Lanka man-made environment that favours the growth of legionellae such as cooling towers are now widespread, especially in hotels and some industrial complexes. So far no studies have been done, to the best of our knowledge, on legionellae in the environment. The present study was done to determine the presence and species composition of legionellae in selected cooling tower systems and the previous exposure of selected hotel workers to the bacterium.

\section{Materials and methods}

Seven hotels were selected from the westem and central provinces for this study. A total number of 16 cooling towers were used for the sampling and 1 to 2 litres of water were collected from the bottom of the each cooling tower. Each sample was concentrated by centrifugation $(6000 \mathrm{~g} \times$ $30 \mathrm{~min}$ ) and $0.1 \mathrm{ml}$ of concentrated sample was inoculated on buffered charcoal yeast extract (BCYE) agar (8) and modified Wadowsky and Yee (MWY) medium (9). Part of the concentrated sample was treated with $0.2 \mathrm{~m} \mathrm{KCI}-\mathrm{HCI}$ acid buffer for 5 minutes at room temperature and $0.1 \mathrm{ml}$ was inoculated as before. Acid treated water samples inoculated on MWY agar plates were used for counting the colony forming units (CFU/ml) of legionellae. All plates were incubated at $37^{\circ} \mathrm{C}$ for 10 to 14 days in the presence of $5 \% \mathrm{CO}_{2}$. Colonies that appeared after 4 days of incubation with a circular (1 to $2 \mathrm{~mm}$ in diameter), moist, smooth glistering surface, entire edge, grey-bluish in appearance, were subcultured on BCYE and 5 to $7 \%$ human blood agar plates. Those that grew only on BCYE agar and not on blood agar were considered as suspected legionellae, and presumptively identified by gram stain appearance, motility, gelatin liquefaction, positive catalase test and non-fermentation of sugars. Fatty acid profiles of some of these isolates were compared with one reference strain of $L$ pneumophila by gas liquid chromatography (GLC) (10). All the profiles were similar to the profile of the reference strain (height of

'Department of Bacteriology, Medical Research Institute, Colombo 8. (Revised version accepted 15 September 2000). 
the peaks varied due to the quantum of the acids produced by bacterial strains; identity of the acids are, however, proven by the retention time) suggesting that the isolates are Legionella (Figure). Presumptively identified strains were confirmed at St. Mariana University School of Medicine, Japan and Centres for Disease Control and Prevention (CDC), Atlanta, USA.

To determine past infection among the hotel workers, blood samples were taken from them and the indirect immunofluorescent test (IFA) was performed with Scimedx legionella (indirect) fluorescent test system (Scimedex Corporation, USA) for each sample according to the manufacturer's instruction. A titre of $\mathbf{2 5 6}$ or more was considered as evidence of past infection (11).

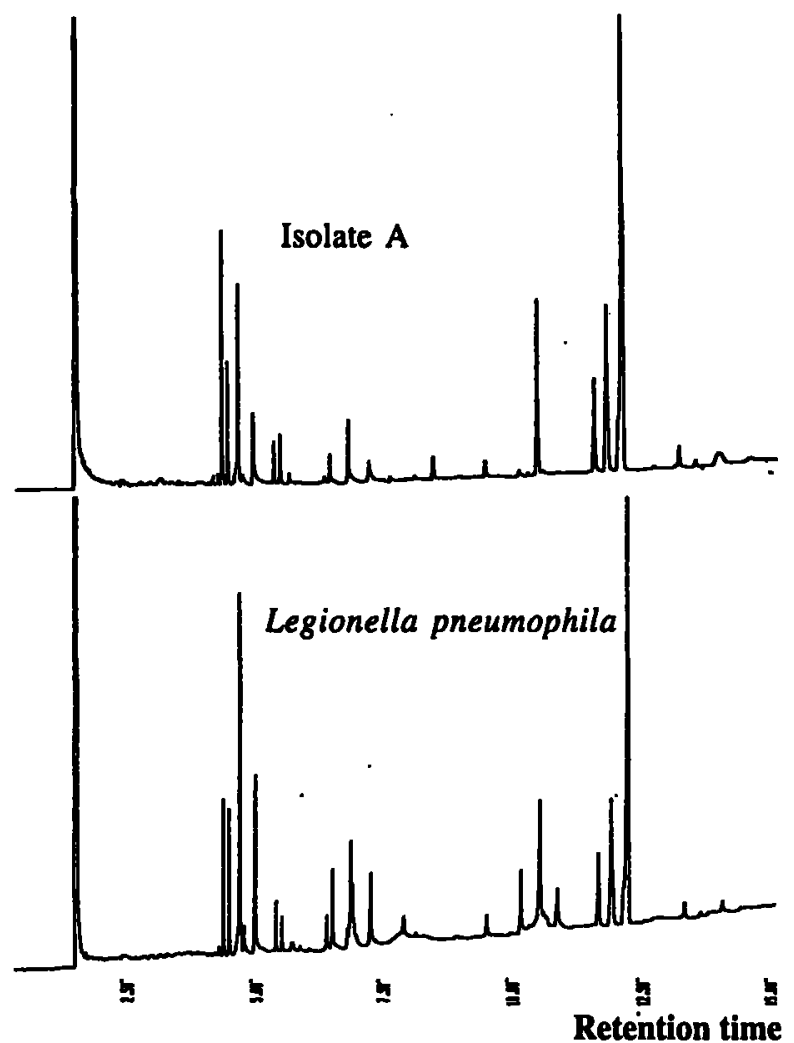

Figure. Fatty acid profile of isolate by GLC

\section{Results}

Legionellae were isolated from $4(57.4 \%)$ out of 7 hotels from 16 cooling towers. Five of them $(38.4 \%)$ yielded legionellae. Viable counts of legionellae of these towers were in the range of 1 to $5 \mathrm{CFU} / \mathrm{ml}$. Total number of isolates was 16 . Most of these isolates $(93.7 \%)$ were L pneumophila. Only one of these $L$ pneumophila was serogrouped and proved to be sg 1 , the most common clinical and environmental isolate recorded world-wide. One strain of these isolates was $L$ rubrilucens which is a non-pathogenic species. Only one blood sample gave an antibody titer of 256 suggestive of past infection.

\section{Discussion}

This is the first study to explore the presence of legionellae in a Sri Lankan environment. The study area was limited to the western and central provinces where many tourist hotels with cooling towers are found. According to the results of this preliminary study $L$ pneumophila does occur in the cooling towers in the country, and it was the most common Legionella species found.

Although $38.4 \%$ of the selected cooling towers yielded legionellae, evidence of past exposure to the organism among the hotel workers was low (1 of 25). One Japanese study reported that viable legionellae had been found in $63 \%$ of their cooling towers and average counts were recorded up to $100 \mathrm{CFU} / \mathrm{ml}(12)$, and $44 \%$ of cooling towers in the UK were reported to contain the bacterium (13). Legionellae counts of between 10 and $20 \mathrm{CFU} / \mathrm{ml}$ in cooling towers were reported by a recent study in Germany (14). Although viable counts of legionellae found in the present study is low (1 to $5 \mathrm{CFU} / \mathrm{ml}$ ), and no epidemics have been reported in the country, further study is required to investigate the factors which lead to Legionella infection, as the various strains of $L$ pneumophila differ in virulence, and multiple strains may colonise the cooling tower systems (6). Only a few of them may cause disease in humans exposed to the contaminated water.

\section{References}

1. Mcdade JE, Shepard CC, Fraser DW, Tasi TR, Redus MA, Dowdle WR. Legionnaire's disease; isolation of a bacterium and demonstration of its role in other respiratory disease. New England Journal of Medicine 1977; 297: 1197-203.

2. Benson RF, Thacker WL, Daneshvar MI, Brenner DJ, Legionella waltersii sp.nov. and an unnamed Legionella genomospecies isolated from water in Australia. International Joumal of Sys. tematic Bacteriology 1996; 46: 631-4.

3. Filermans CB, Cherry WB, Orrison LH, Smith SJ, Tison DL, Pope DH. Ecological distribution of Legionella pneumophila. Applied and Environmental Microbiology 1981; 41: 9-16.

4. States SJ, Conley LF. Kuchta JM, Oleck BM, Lipovich MJ, Wolford RS, et al. Survival and multiplication of Legionella pneumophila in municipal drinking water system. Applied and Environmental Microbiology 1987; 53: 1775-9.

5. World Health Organization. Epidemiology, prevention and control of Legionellosis; Memorandum from WHO meeting. Bulletin of World Health Organization 1990; 68: 155.64.

6. Plouffe JF, Para MF, Maher WE, Hackman B, Webster L. Subtypes of Legionella pneumophila serogroup 1 associated with different attack rates. Lancet 1983; 2: 649-50.

7. Wickramasinghe RSB. Legionnaire's disease. A report on two cases. Annual Academic Sessions of the Sri Lanka College of Microbiologists, 1993.

8. Edelstein PH. Improved semiselective media for isolation of legionella pneumophila from contaminated clinical and environmental specimen. Journal of Clinical Microbiology 1981; 14: 298-303.

9. Edelstein PH. Comparative study of selective media for isolation of Legionella pneumophila from potable water. Journal of Clinical Microbiology 1982; 16: 697-9.

10. Christie W. Lipid analysis. 2nd ed. New York: Pergamon press, 1982: 22-52.

11. Centres for Disease Control and Prevehtion. Case definition of Legionellosis. Morbidity and Mortality Weekly Repon 1990; 39/No RR-13: 18.

12. Ikedo M, Yabunchi E. Ecological studies of Legionella species: viable count of $L$ pneumophila in cooling tower water. Microbiology and Immunology 1986; 30: 413-23.

13. Bartlett CLR, Kurtz JB, Hutchinson JGP, Turner GC, Wright AE. Legionella in hospital and hotel water supplies Lancet 1983; 2: 1315 .

14. Christain LC, Hans-Martin W, Jurgen HN. Nosocomial pneumonia caused by three genetically different strains in the hospital water supply. Journal of Clinical Microbiology 1998; 36: 1160-3. 